\title{
O SURGIMENTO DO CORREIOS DO BRASIL COM A PRIVATIZAÇÃO DA ECT
}

\author{
Edson Ricardo Saleme* ${ }^{1}$ \\ Renata Soares Bonavides**2 \\ José Marcelo Grimone***3
}

\section{Resumo:}

A ECT é empresa pública que comprovadamente acumula grande deficit em termos de obtenção de receita, sobretudo em face de sua perda diante das novas tecnologias. O PL 591, de 2021, é uma tentativa de ato que pode conduzir a uma gestão adequada de uma empresa que não se enquadra na perspectiva do que dispõe a Lei n. 13.303, de 2016, cujo intuito é dinamizar várias frentes em termos de estatais. Por meio de uma abordagem documental e bibliográfica e pelo método hipotético-dedutivo, busca-se possível solução para a crise atualmente enfrentada com a privatização que segue modelos adequados anteriormente adotados.

Palavras-chave: ECT; privatização; lucro; Correios do Brasil; déficit

\section{PRIVATIZATION OF THE POST COMPANY AND THE BEGINIG OF "CORREIOS DO BRASIL}

\begin{abstract}
:
ECT is a public company that has proven to accumulate a large deficit in terms of obtaining profit, especially in view of its loss due to new technologies. PL 591, of 2021, is an attempt at an act that can lead to an adequate management of a company that does not fit in the perspective of Law 13.303, 2016, whose purpose is to dynamize several possibilities in terms of state-owned companies. Through a documental and bibliographic approach and through the hypothetical-deductive method, a possible solution to the crisis currently faced with privatization is sought, following adequate models previously adopted.
\end{abstract}

Keywords: ECT; privatization; profit; Brazilian post office; deficit

\section{1 - INTRODUÇÃO}

A presente Constituição trouxe a necessária forma neoliberal de atuação estatal, pelo qual este deixa de ser agente interventor direto na economia e se materializa em agente

\footnotetext{
${ }^{1}$ Professor Doutor em Direito do Estado pela USP, pós-doutor pela UFSC, consultor do IBAMA, professor do Curso Stricto Sensu em Direito Ambiental Internacional da Universidade Católica de Santos. E-mail: ricasal@unisantos. br

**2 Diretora da Faculdade de Direito da UNISANTOS, professora do Curso Strcto Sensu em Direito Ambiental internacional da Universidade Católica de Santos, Doutora pela PUC-SP, advogada em Santos. E-mail: renatasbonavides@gmail.com

***3 Coordenador do Curso de Direito da UNITALO. Doutor em Direito pela PUC-SP, advogado em São Paulo. Email: marcelojosegrimone@hotmail.com
} 
normativo e regulador, passando a criar regras e diretrizes próprias em prol do desempenho dos serviços e consumidores para que as concessionárias atuem adequadamente, de forma a propiciar ao usuário segurança jurídica e também bons serviços.

O art. 173 deixa claro quando a intervenção do Estado pode ocorrer. Porém, o número de estatais federais hoje existente é bem significativo e sua contribuição para diversos setores da economia naconal é inegável. Não se pode deixar de observar a importância e necessidade que diversos segmentos têm pelo desempenho de serviços e disposição de bens prestados por essas empresas

O poder público, portanto, trabalha com a possibilidade de atuação direta e assim, como referido, a Constituição permite em casos em seja justificável, ou melhor, nos casos em que imperativos de segurança nacional ou relevante interesse coletivo estejam diretamente envolvidos, em termos definidos por lei.. Porém, são exceções e devem ter justificativa própria, capaz de viabilizar o desempenho da atividade econômica pelo ente estatal.

Ao lado de fatores puramente jurídicos e, em busca der melhores e mais significantes resultados, as entidades estatais da administração de toda federação têm buscado analisar suas atividades a fim de, eventualmente, alterar o escopo de suas próprias atividades com o intuito de obter lucros mais significantes. Por vezes reavaliam suas funções diante das mutações tecnológicas ou mesmo do mercado, sobretudo após as alterações geradas pela pandemia, cujos resultados negativos são revelados diariamente em nossa realidade.

A continuidade de suas atividades, no todo ou em parte, devem ser planejadas e reajustadas de tal forma que os cofres públicos possam receber o benefício da atividade econômica.. Também precisam atender às funções sociais, pois as atividades estão atreladas ao governo e a sociedade e ainda obter resultado econômico. Assim, mesmo as empresas de capital exclusivamente público devem cuidar de seu patrimônio, até mesmo em face da inadimplência estatal no pagamento de suas obrigações.

Há atividades, tal como as bancárias, que disputam parcela de mercado com empresas privadas de portes similares, de grande capacidade de reinvestimento e maior flexibilidade de ações, com poder de resposta rápida às oscilações de mercado; estas importam não somente a Administração que pertencem, mas também proporcionam cargos e salários, fundamentais 
para a sociedade atual. Sua eventual privatização pode reduzir esse número que sofre reduções a cada crise econômica ou sanitária.

A Empresa Brasileira de Correios e Telégrafos é objeto deste estudo no sentido de ser privatizada da forma mais breve possível. Vários fatores estão envolvidos em seu programa de privatização que, se não forem atendidos, podem fazê-la cada vez menos atrativa aos possíveis compradores. A questão que se coloca é se realmente será positiva essa privatização nas diversas dimensões de mercado. A manutenção de sua administração pelo Poder Público pode ou não ser uma opção adequada. Talvez a resposta possa vir rapidamente, bastando para tanto rememorar ações inescrupulosas que culminaram na responsabilização criminal dos antigos gestores da administração federal se iniciaram na ECT, que culminou com atos investigativos, que hoje muitos preferem olvidar.

A atual administração federal tem o intuito de vendê-la, juntamente com tantas outras empresas estatais, cerca de 17 , tal como revelou o atual ministro da economia. A verdade é que os Correios estão nessa lista e o passar do tempo vem sucateando mais e mais sua frágil estrutura. Mesmo diante de estudos aprofundados, como aqui será visto, e afirmações peremptórias em termos de viabilidade financeira, colocam essa Empresa, com tradição no universo nacional, na lista das vendáveis.

A questão que aqui se coloca é acerca da conveniência ou não, considerando o interesse coletivo, na privatização da Empresa Brasileira de Correios e Telegrafos (ECT) e o que sua manutenção pode gerar em termos de prejuízo na administração pública. O método será o hipotético-dedutivo, a metodologia bibliográfica e documental, sobretudo na dinâmica empreendida pela própria União, que detém seu capital, no sentido de levantar a conveniência ou não de sua manutenção, sobretudo em face de serem os serviços prestados sob monopólio, cada vez menos utilizados pelos utentes do serviço oferecido.

A problemática envolve questões discricionárias entre outras consideradas de importância cardeal. Porém, o trabalho se centrará no conteúdo legislativo em prol da boa condução das empresas estatais e como podem ter bom rendimento em sua condução e resultados efetivos pela própria administração pública. Outro aspecto a ser abordado é o conflito natural entre público e privado, sobretudo após a edição da Lei n ${ }^{\circ} 13.303$, de 2016, que estaberlece o estatuto jurídico da empresa pública, da sociedade de economia mista e de 
suas subsidiárias, no âmbito da União, dos Estados, do Distrito Federal e dos Municípios. Aspecto que desde já se refuta é a possível inconstitucionalidade da privatização, por ser este possível serviço reservado à União. Na verdade, a transferência é a simples outorga de prestação do serviço e não do serviço, que sempre se manterá da maneira que está, com uma agência reguladora na fiscalização de serviços adequados.

\section{2 - A ECT E SUA ATUAL ACONDUÇÃO}

A presente empresa é fruto de uma reorganização ocorrida no século passado. A necessidade de readequação à realidade social e a novos métodos empresariais, sobretudo no que tange ao regime trabalhista de seus empregados e também à possibilidade de expansão de agências, deu a ECT um novo impulso, que viabilizou sua reestruturação muito próxima de como atualmente se apresenta. Posteriormente, a diversificação passou a ser uma das metas a serem atingidas pela empresa, uma vez que seus serviços monopolizados não alcançavam resultados de outrora.

A empresa está presente em todos os municípios brasileiros; desenvolve atividades distribuídas em áreas próprias, que podem ser divididas em: operacional e de suporte/administrativa. A primeira concentra atividades-fim da própria empresa, que consiste basicamente no atendimento (vendas), tratamento (cargas e encomendas) e entrega (distribuição). Sua função também está conectada com o comércio exterior, por meio da importação e exportação de produtos com países com os quais o Brasil mantém relações comerciais (ECT,2021)

A reestruturação teve origem desde o surgimento do Código Postal Universal, redigido no IX Congresso Universal em Londres, em 1929. Este buscou possíveis soluções para os problemas postais da época e assim modelando os correios tal como se apresentam atualmente, sobretudo no que tange ao oferecimento de produtos e serviços. A Revolução de 30 alterou profundamente a estrutura político-administrativa do País e também atingiu o setor postal, que acompanhava os câmbios da época. Novas mudanças impactaram a prestação de serviços dos Correios, que modificou sua estrutura técnica de forma a atender necessidades aliadas à comunicação tal como a criação do Departamento de Correios e Telégrafos (DCT) o que, posteriormente, incorporou-se à prestação dos demais serviços da empresa (2013). 
Essa reorganização do século XX, como sublinhou Teixeira (2014), estabeleceu a Empresa Brasileira de Correios e Telégrafos (ECT) pelo Decreto-Lei no 509, de 20 de março de 1969. Sua composição como empresa pública resultou do impulso dado pela reforma administrativa do Decreto-Lei no 200, de 1967. Esta gestão buscava dar a ECT uma gestão compatível com suas necessidades, de forma a proporcionar ao setor postal mecanismos de direito privado. Seu patrimônio pertence integralmente à União e possui autonomia gerencial capaz de buscar obtenção da resultados por meio de suas operações empresariais.

Nesse contexto, a Lei $\mathrm{n}^{\circ} 13.303$, de 2016, ao se preocupar com as boas práticas de governança nas empresas estatais de todas as unidades federativas, trouxe novas perspectivas e desafios, sobretudo em forma de governança. Para tanto, prestigiou o uso das ferramentas empresariais disponíveis para fins de mitigar ingerências políticas sofridas. Nessa toada, antigas formas de controle pautadas por um dirigismo estatal exógeno cederam para que órgãos internos da empresa pudessem adequadamente conduzir os seus atos negociais relacionados ao objeto, inclusive no que toca a consecução de sua missão pública. Ademais, a Lei das Estatais demarcou as fronteiras para a sua utilização como promotora de políticas públicas no âmbito da sua finalidade institucional, incrementando, portanto, importantes ajustes ao então figurino empresarial utilizado pelo Estado.

Atualmente existem duas correntes divergentes que se posicionam contrariamente no quesito privatização. Como é claro, os Correios, como empresa que monopoliza serviços públicos de cartas e telegramas está em queda acentuada, pois seus serviços foram substituídos por outras formas mais ágeis e simplificadas. Portanto, a demanda é cada vez menor e as receitas decrescentes. Existe considerável patrimônio dedicado a uma atividade em descenso. A parte que mais se acentua em termos de negócios, a de encomendas, possui ampla concorrência no mercado. Considerando sua condição de empresa estatal, a concorrência não é seu forte, pelas imposições e próprias características da categoria, o que pode conduzir a empresa a um colapso total.

É certo que existe grande desvantagem nesse setor de entregas e há parcela considerável do mercado que a desafia em termos de concorrência, não obstante o serviço de qualidade que possa atualmente oferecer, pois a tendência é que o monopólio não tenha como manter a empresa. $\mathrm{O}$ mercado de logística está em franca atividade como se pode nitidamente 
observar, sobretudo com a ascensão do comércio eletrônico, que valorizou sobremaneira as empresas de logística.

\section{3 - OBJETIVOS DA EMPRESA}

Os objetivos empresariais podem ser de curto, médio e longo prazo. O planejamento estratégico deve ser efetivado com base em períodos especiais, em se definirá as ações a serem tomadas a fim de que se alcancem os objetivos propostos; podem inclusive estabelecer quem tomará as decisões, de que forma deveriam ser realizadas e os eventos que as oportunizariam.

Na implementação de estratégia há conceitos influenciadores de sua execução, nas palavras de Hitt, Ireland e Hoskinsson (2008), a exemplo da governança corporativa, que tem por base a formulação de estratégias a serem implementadas estratégias e cujo intuito seria auxiliar a empresa a ganhar competitividade estratégica e obter recursos esperados; também estes se relacionam com estruturas e controles organizacionais capazes de direcionar tomadas de decisões próprias em face dos objetivos estratégicos e financeiros propostos; isso também leva em consideração a liderança estratégica, cuja habilidade requer a possível ocorrência de eventos, possibilidades, e permitir que outros proponham mudanças estratégicas e empreendedorismo estratégico.

Mintzberg (2001) questiona em suas discussões acerca da boa gestão no mundo empresarial quem deve controlar a empresa? A discussão acerca do controle corporativo acarreta, na verdade, infindáveis reflexões. Nessas discussões fez-se uma composição analógica no sentido de buscar traçar no mundo empresarial uma fórmula eficaz ou, ao menos, passível de inspiração. Desta constatação originou-se o modelo de ferradura com o possível forma capaz de inspirar o mundo empresarial. No contexto, a ferradura representa as diversas dimensões existentes em uma empresa, desde sua lida política no mundo empresarial até sua inserção nacional e internacional. Ainda, sua utilidade, reflete possível o modelo de governança adotado pela empresa, que deve ser compatível com suas aspirações e possibilidades. A ECT, como qualquer outra empresa, deve estar atenta à movimentação do mercado e a aceitação de seus produtos, que não giram apenas em monopólio, o que não representa mais algo que lhe assegure retorno de capital. Por este motivo não resta outra 
alternativa senão inspirar-se nos modelos empresariais privados a fim de neles retirar o melhor substrato para conduzir seus negócios e possíveis ações a serem tomadas.

Há destaques na necessidade de mudança e adaptação das empresas de correios e telégrafos. Teixeira (2014) indica motivos alegados por diversas instituições de forma a melhor adequar a regulação do setor postal e suas diretrizes; isto pode ser recomendado:

[...] por agências internacionais como o Banco Mundial, União Postal Universal (UPU), Organização para a Cooperação e Desenvolvimento Econômico (OCDE) e Fundo Monetário Internacional (FMI). Em um relatório do Banco Mundial preparado com o auxílio da UPU e publicado em 1996, intitulado Redirecting mail: postal sector reform, foram apresentados as razões pelas quais as administrações postais deveriam ser transformadas e os caminhos a seguir. Dentre eles, o Banco Mundial listou a suposta ineficiência e inadequação dos operadores públicos às necessidades do mercado e da população. Os correios estatais, afirmou o Banco Mundial, não proporcionavam rentabilidade até mesmo para investimentos na melhoria dos serviços, o que motivou diferentes governos a buscarem reformas para o setor (Ranganathan e Dey, 1996). Nesse sentido, a Ocde (1999:21, tradução nossa) argumenta que

Mazzali et al (2014) refletem acerca dos passos mais avançados da ECT em vista de melhor diversificação. Destacam que, no inicio da década de 1990, mais de 90\% da empresa estava dedicada nos segmentos mais tradicionais, ou seja, "cartas e impressos simples, franqueamento, telemáticos e correio híbrido postal, encomendas (Sedex, Sedex 10, Sedex Hoje e reembolso postal), filatelia, serviços e produtos de conveniência e internacional (exporta/importa fácil e mala direta internacional).“

A dependência desses segmentos resultou de estratégia da época, que permaneceu até meados de 1994, cuja ênfase estaria na melhor integração nacional e no incremento da qualidade dos serviços prestados, no sentido de que houvesse maior agilidade e rapidez na entrega. Os autores ainda destacam que desde a criação da Empresa Brasileira de Correios e Telégrafos, em 1969, não se pouparam esforços no sentido de se voltar inteiramente à melhor integração e desenvolvimento de novos avanços tecnológicos. Criou-se, nesse período, o Serviço Especial de Entrega de Documentos (SEED), o Serviço de Entrega de Correspondência Agrupada (SERCA) e os Serviços Expressos (SEDEX) (MAZZALI ET AL, 2014).

O esquema operacional da empresa para o atendimento dos serviços de correio convencional seria relativamente simples. Entretanto, o tamanho do país e o grande número de atividades desenvolvidas pela empresa gera logística extremamente dificultosa, que se 
inicia nas unidades de recepção de material até sua destinação final, que inclusive conta com as agências franqueadas, que colaboram efetivamente com a melhor prestação dos serviços.

\section{4 - OPÇÕES DA ECT NO MERCADO}

O mercado apresenta-se competitivo e inovador. A ECT possui receita oriunda de mercado não monopolizado; é fundamental a reorganização permanente da empresa a fim de se reinventar, de maneira a manter-se atualizada e pronta a continuar com suas ações de maneira a ser competitiva e ter lucratividade adequada em suas atividades empresariais. $\mathrm{O}$ relatório apresentado pelo BR Partners apresenta avaliações econômico-financeiras independentes para a operação de desestatização dos Correios, com a supervisão final do BNDES (Ministério da Fazenda, 2021).

Segundo as informações do Departamento de Coordenação e Governança das Empresas Estatais do Ministério do Planejamento, Orçamento e Gestão (2021) têm sido realizados estudos coordenados pelo BNDES com a supervisão do Comitê Interministerial, nos termos do Decreto $\mathrm{n}^{\mathrm{o}}$ 10.066, de 2019, que incluiu os Correios no Programa de Parcerias de Investimentos (PPI).

O Decreto $n^{\circ}$ 10.066, de 15 de outubro de 2019, estabelece em seu art. $1^{\circ}$ a Empresa Brasileira de Correios e Telégrafos - ECT como qualificada no âmbito do Programa de Parcerias de Investimentos da Presidência da República - PPI, para possibilitar a realização de estudos e a avaliação de alternativas de parceria com a iniciativa privada e propor ganhos de eficiência e resultados para a empresa, com vistas a garantir sua sustentabilidade econômicofinanceira. $\mathrm{O}$ intuito seria basicamente viabilizar o nível da empresa e sua possibilidade de ser levada à privatização.

O PL 591, de 2021, em tramitação no Congresso Nacional, que objetiva a privatização dos Correios, dispõe acertadamente sobre todos os itens necessários à organização e a manutenção do Sistema Nacional de Serviços Postais (SNSP). Segundo suas diretivas, que incorporam a conceituação dos diversos serviços prestados e que inclusive aumentam a qualidade dos serviços postais, garantem a prestação do serviço universal, amplia investimentos privados no setor e, por fim, autoriza, no art. 30, a desestatização da Empresa Brasileira de Correios e Telégrafos (ECT) com alienação de controle societário em ocnjunto 
com a concessão de serviços postais outorgando a ANATEL e modificando a propria designação como Correios do Brasil (parágrafo único art. 30, I)

Estudos realizados pelo DIEESE (2021) os Correios - ECT é um grupo de destaque entre empresas públicas. Possui atuação nos municípios brasileiros, por suas 12 mil agências e mais de 100 mil empregados. Atuam na entrega de correspondências, possui o banco postal, emite documentos diversos, distribui vacinas, entrega provas (ENEM) e milhões de livros didáticos, isso sem contar com serviços de importação e exportação. Neste momento passa por grande expansão devido ao comércio eletrônico existente e na reconfiguração dos setores de comércio e logística em nível internacional.

Em estudo voltado ao contexto organizacional e desdobramentos da estratégia de inovação, observa-se que a Empresa Brasileira de Correios e Telégrafos (ECT) se encontra em setor altamente competitivo e impactado, mormente diante das contínuas transformações digitais continuamente presentes no panorama hodierno. Considerando a premência de inovação de forma a manter a competitividade as empresas do setor postal, do setor logístico e de encomendas deve estabelecer estratégias inovadoras a fim de obter vantagens competitivas, que possam torná-las referência naquele setor.

Amorim (2019) em sua monografia traça algumas recomendações diante da necessidade de inovação e premência de modernização em face da extrema competitividade do setor. A recomendação é

[...] obter o apoio e o compromisso da alta gestão da empresa como base para que uma estratégia de inovação possa ser formulada e implantada, assim, recomendamos que a estratégia de inovação da organização seja patrocinada pela presidência. Recomenda-se ainda, avaliar o nível de maturidade em gestão da inovação da empresa, e traçar em detalhes as ações estratégicas de inovação, de forma a usar os mecanismos habilitadores internos e externos de inovação, além disso, se faz necessária uma definição formal da estratégia de inovação alinhada à estratégia da empresa, de forma a assegurar que não sofra ingerências politicas. A recomendação é realizada com base em observações do autor sobre a organização. Verificou-se que são constantes as mudanças na estrutura organizacional e muitas iniciativas importantes podem ser descontinuadas nesses processos

Em estudos feito pelo IPEA não importa o nível e a complexidade da empresa estatal federal na economia nacional. A longa tradição dessas empresas impõe, necessariamente, entendimento mais aprofundado acerca de sua atuação e de uma agenda de estudos e pesquisas orientadas que possam melhor visualizar a presente configuração, os padrões de 
desempenho e os modelos viáveis de governança que possam ser aplicados. e 133 empresas estatais federais. Nos estudos feitos por Pellegrini (2019) das 115 estatais federais não dependentes, 28 são de controle direto da União, enquanto 87 são subsidiárias de outra estatal federal. Mais adiante o autor tece considerações acerca da possibilidade de melhoria diante da nova lei das empresas, referida no início deste trabalho, no sentido de que melhorou alguns prazos, contratações. Porém, segue com o procedimento que o autor indica como "burocrático" e falta de regulamentação a temas relevantes.

Ainda que existam diretivas em prol de ações necessárias para que, efetivamente, as empresas possam atingir sua função social, há um limite que deveria ser observado pelos administradores. Parece inadequado a manutenção de empresa que possa gerar grande déficit ao erário. É certo que não se pode perder de vista a contribuição que traz à sociedade com a geração de empregos diretos, indiretos e outras possibilidade no que concerne a atividade empresarial.

\section{5- A MISSÃO DA LEI ${ }^{\circ} 13.303$ de 2016}

Esta análise se circunscreve a duas normas importantes em termos de estatais: o próprio conteúdo das Lei n ${ }^{\circ}$ 13.303, de 2016 (Estatuto das Estatais ou Lei das Estatais), que reitera a necessidade de governança por parte das empresas estatais, como indicativo fundamental para seu funcionamento. Enfoca-se ainda no artigo 27 da Lei, que reitera a função social de realização do interesse coletivo ou de atendimento a imperativo da segurança nacional, que tenha sido expressa possivelmente na autorização legislativa que viabilizou sua existência.

A Lei 13.879, de 2019, a "Declaração de Direitos de Liberdade Econômica" também é fundamental no exame de funcionamento das estatais e da necessidade ou não de sua privatização, o que muitas vezes pode influenciar decisivamente no exame discricionário de conveniência de manutenção de determinadas estatais com o Poder Público.

Fontes Filho (2018) esclarece que no Brasil, seja pelo grande volume de ativos e da importância econômica essencial das empresas estatais, considerando as empresas de qualquer nível federativo, observa-se a grande importância diante das diversas dimensões sociais, econômicas e políticas nela existentes. Na questão social, a geração de empregos e políticas de pessoal, estão em nível muito superior que as oferecidos no mundo privado; trata-se de 
forma de influência positiva. Na questão econômica pode-se dizer que, em sua grande maioria, operam em condições de ausência de interesse em mercado determinado ou ainda quando a relevância pública justificar. Para o autor "[...] Seguindo as definições correntes, eficiência direciona a adequada gestão dos recursos em relação às atividades, ou a competência para produzir resultados com o menor uso de recursos e esforços, enquanto efetividade remete à capacidade de atingir os resultados pretendidos."

Nos termos dispostos no art. 27 da Lei n 13.303, de 2016, os atos das empresas estatais estão sujeitos à estrita observância do principio da função social de realização do interesse coletivo da empresa. Por este motivo, sob o escólio de Fontes-Filho (2019) a competitividade das empresas estatais pode ser prejudicada pelo atendimento dos requisitos de "[...] transparência, prestação de contas, fiscalização e análise por auditorias externas, de limites à internacionalização e diversificação e restrições na seleção de fornecedores (principalmente se internacionais) [...] em sua atuação, a estatal tem baixa autonomia.”

Outro fator que chama a atenção é a preocupação da Lei na questão da chamada "governança corporativa", o que pode colocar em risco ao que se denomina "problema de agência", significando o natural choque ou conflituosidade entre público e privado. Isso porque os stakeholders envolvidos não estão apenas entes estatais, estão parceiros privados que tem no lucro seu objetivo final e não outros papéis que a empresa estatal possa prestar, a exemplo de boas práticas a serem seguidas pelas empresas privadas (FORTINI; SHERMAN, 2016).

A expressão remarcada por Di Pietro (2016) de que o poder público nacional em termos de optar por institutos de direito privado se denominaria "fuga do direito público ou fuga para o direito privado". Com isso crescem as parcerias com entidades privadas e redução de cláusulas exorbitantes. Contudo, nem sempre o regime privado pode ser incorporado inteiramente pela Administração Pública, pois o regime é sempre derrogado. A autora esclarece que essa "fuga" foi remarcada por Maria João Estorninho a fim de retratar que ela não é feita com "cara boa" mas sim com "cara má" a fim de fugir da sujeição do regime publicístico. Isto nem sempre se externaliza com bons resultados.

A governança tem como um dos principais objetivos a possível solução do chamado problema de agência e busca conciliar interesses e ainda tem como objetivo a possível 
agragação de valor ao negócio e ampliarção da obtenção de recursos e investimentos, contribuindo para a qualidade da gestão e perenidade das organizações.

Pela avaliação da situação financeira da empresa de correios elaborada pela Controladoria Geral da União (2019). Essa avaliação efetivou-se em decorrência do fato de que desde 2013 a ECT já acumulava consideráveis perdas. Nesse sentido buscou-se diagnosticar elementos que pudessem traçar um diagnóstico da situação econômico-financeira da empresa e, assim, verificar os motivos dos resultados desfavoráveis. Nesse período, constatou-se crescente degradação da Liquidez, aumento do endividamento e da dependência de capitais de terceiros. Talvez o mais preocupante seja a redução sistemática da rentabilidade, com a geração de prejuízos crescentes.

O Relatorio $\mathrm{n}^{\mathrm{o}} 201700921$ (2017) aponta que devido ao fato de serem substituídas as mensagens físicas por digitais a redução anual de correspondência reduziu drasticamente. Pelo que foi apontado em uma ordem de 3,4 para 2,7 bilhões de objetos transportados. Isso representa uma redução da ordem de $20 \%$. A indicação seria o aumento da tarifa para compensar as perdas no curto e médio prazo.

Em face dessa realidade e observando que o serviço de encomenda, ao contrário do serviço postal, não se submete a monopólio estatal, já recomendou-se que os Correios mantivessem investimentos permanentes para não perder a competitividade frente aos demais que prestam serviço idêntico no mercado. Tudo depende de efetiva melhora nas condições de eficiência, sobretudo pela presente situação financeira.

Aqui abordou-se a realidade do fato de que a situação dos Correios é preocupante, sobretudo diante de sua posição e do investimento público que representa. Os relatório não deixam de revelar a preocupação dos gestores federais na venda dos ativos enquanto é tempo. Caso a empresa venha a se sucatear, pouco ou nada valerá. Diante dessas evidência não há como deixar passar o presente momento e vender seus ativos.

Aspecto que merece também ser relevado é que a empresa é vítima permanente de um processo de corrupção por parte de seus dirigentes e outras autoridade envolvidas. Há dois relatórios confidenciais que comprovam desvios muito significativos por parte da Previc (Superintendência Nacional de Previdência Complementar). Nesse cenário, mais um motivo 
de grande importância para a empresa ser repassada. Certamente, um grupo privado terá maior zelo na condução de todas as verbas manipuladas pela empresa (ROMANO, 2019).

\section{6 - CONSIDERAÇÕES FINAIS}

A ECT é empresa que possui monopólio estatal. Conforme consagra a Constituição Federal. A privatização da empresa representa a simples transferência da prestação de serviço por meio da outorga deste a empresa que atenda os requisitos legais e possa contar com corpo de empregados adequados para prestá-lo dentro das especificações indicadas na norma. Esta reserva estabelecida em favor da União, qual seja, o transporte de cartas e encomendas a elas equiparadas, confere uma exclusividade e monopólio em termos de serviços específicos. Sua constituição está estabelecida como empresa da administração indireta da União criada pelo Decreto-lei no 509, de 10 de março de 1969. Em decisão do STF já existe o reconhecimento de que presta serviço público obrigatório e não atividade econômica, como se chegou a cogitar.

O serviço postal e as atividades prestadas atualmente pela Empresa Brasileira de Correios e Telégrafos já está alinhado em termos normativos e todos os pareceres realizados a fim de verificar seu desempenho, demonstram o risco de maior perda, na hipótese de o Poder Público decidir manter a empresa pública. Aliás o que se buscou demonstrar é que existem diversos pareceres emitidos por agências públicas indicando o estado deficitário e a progressão deste com o passar dos anos em face da defasagem gerada por aspectos próprios de empresas públicas.

Existe, como referido neste trabalho, o conflito entre interesse público e privado, natural nas prestações de serviços públicos desempenhados por concessionários ou outros que venham a substituir o poder público na "prestação" do serviço. Quer dizer que o poder público não possui função essencialmente empresarial. Há também um objeto prestacionista com cunho social, que viabiliza a geração de empregos, prestação de serviços, teoricamente, com valores razoáveis e acessíveis. Este sim é fator a ser considerado, uma vez que a empresa, nos termos prescritos pela Lei ${ }^{\circ} 13.303$, de 2016, possui função social essencial no tocante a esses elementos, que não poderiam ser desconsiderados.

Por outro lado, não se pode deixar de ter olhos abertos para a realidade corrente. A empresa acumula prejuízos e possui déficit crescente, conforme bem delineiam os relatórios 
mencionados neste trabalho. Não é uma conjectura. A empresa está em um momento complexo pois o que lhe garante mercado não é seu serviço monopolizado, mas sim o que presta em concorrência com o mercado. Como reforçam os relatórios, gerados para demonstrar seu frágil estado econômico, sua capacidade é limitada para enfrentar modernizações súbitas ou mesmo outras dinâmicas de mercado que possam reduzir ainda mais a capacidade que a empresa atualmente possui.

As empresas estatais receberam dinâmica própria a partir da promulgação da Lei $\mathrm{n}^{\circ}$ 13.303, de 2016. Não podem e nunca foram consideradas despreparadas para enfrentar o mercado. Contudo, mecanismos próprios instituídos por lei, impõe determinadas regras a fim de evitar sejam empregadas para fins eleitoreiros ou que possam inviabilizar sua própria estrutura. Há dois bancos estatais que, não obstante possam ter alguns serviços prestados de forma monopolizada, são competitivos. Enfrentam o mercado e logram captar e capturar clientes de instituições privadas pelo trabalho de excelência realizado por alguns dirigentes. Por outro lado, sua direção nem sempre é criadas por profissionais com experiência e muitas vezes sofrem golpes que podem reduzir totalmente seu capital competitivo.

Não se pode também olvidar que muitas empresas estatais podem ser objeto de troca por parte de ações inescrupulosas provenientes de pessoas que detém poder, tal qual a experiência relatada no Fundo de Previdência dos Correios, cujo capital teve acentuada diminuição em decorrência de golpes sistemáticos.

Diante de todos esses elementos, considerando o quadro atual e os grandes desafios que a ECT deve enfrentar no futuro, não parece despontar alternativa, mas sim apenas uma decisão que pode efetivamente atender o interesse público. Manter empresa cujos ativos se reduzem e cujas perspectivas não são muito promissoras inviabilizam a discricionariedade e levam a uma ação única que seja efetivamente capaz de atender o interesse da coletividade.

\section{REFERÊNCIAS}

AMORIM, Thiago Santos do. Análise e proposições críticas para a formulação da estratégia e da política de inovação na Empresa Brasileira de Correios e Telégrafos. Dissertação para obtenção do grau de Mestre em Propriedade Intelectual e Transferência de Tecnologia para Inovação, do Programa de Pós-Graduação em Propriedade Intelectual e Transferência de Tecnologia para Inovação (PROFNIT), 2019. Universidade de Brasília, sob orientação do Prof. Dr. Edilson da Silva Pedro, 90 fls., 2019. 
BRASIL. Constituição da República Federativa do Brasil de 1988. Brasília. 1988. Disponível em: http://www.planalto.gov.br/ccivil_03/Constituicao/Constituicao.htm. Acesso em: 2 set. 2021.

BRASIL. Decreto $\mathrm{n}^{\mathrm{o}}$ 10.066, de 15 de outubro de 2019, dispõe acerca da qualificação da Empresa Brasileira de Correios e Telégrafos - ECT no âmbito do Programa de Parcerias de Investimentos. Disponível em: https://www.planalto.gov.br/ccivil_03/_Ato2019-2022/2019/Decreto/D10066.htm. Acesso em: 27 set. 2019.

BRASIL. Lei $\mathrm{n}^{\mathrm{o}} 10.650$, de 16 de abril de 2003. Disponível em: http://www.planalto.gov.br/ccivil_03/LEIS/2003/L10.650.htm. Acesso em 6 set. 2020.

BRASIL, Lei n. 12.527, de 18 de novembro de 2011. Disponível em: http://www.planalto.gov.br/ccivil_03/_ato2011-2014/2011/lei/112527.htm. Acesso em: 10 set. de 2020.

BRASIL. Lei $\mathrm{n}^{\circ}$ 13.303, de 30 de junho de 2016. Estatuto jurídico da empresa pública, da sociedade de economia mista e de suas subsidiárias, no âmbito da União, dos Estados, do Distrito Federal e dos Municípios. Disponível em: http://www.planalto.gov.br/ccivil_03/_ato2015-2018/2016/lei/113303.htm. Acesso em: 10 set. 2021.

BRASIL. Lei $n^{\circ} 13.874$, de 20 de setembro de 2019. Declaração de Direitos de Liberdade Econômica. Disponível em: http://www.planalto.gov.br/ccivil_03/_ato20192022/2019/lei/L13874.htm. Acesso em: 10 set. 2021.

BRASIL. Ministério da Economia. Estudos para a desestatização dos Correios avançam com nova contratação de avaliação financeira. Disponível em: http://www.gov.br/economia/pt-br/assuntos/noticias/2021/julho/estudos-para-desestatizacaodos-correios-avancam-com-nova-contratacao-de-avaliacao-financeira. Acesso em: 27 set 2021.

BRASIL. Ministério da Transparência e Controladoria-Geral da União. Relatório $\mathrm{n}^{\circ}$ 201700921. Avaliação da situação econômica e financeira da ECT - Empresa Brasileira de Correios e Telégrafos. Exercícios 2011-2016.

DI-PIETRO, M. S. Z. Transformações do direito administrativo. Revista de Administração Pública. Universidade Federal Fluminense, a2, v.2, n.1, jan/jun,2016.

DIEESE. Departamento Intersindical de Estatísticas e Estudos Econômicos. Uma visão panorâmica das empresas estatais federais e possibilidades de atuação no pós-pandemia. Nota técnica n. 253, março 2021. Disponível em: http://www. dieese.org.br/notatecnica/2021/notaTec253Estatais.pdf. Acesso em: 18 set. 2021.

ECT - Empresa Brasileira de Correios e Telégrafos. História dos correios no Brasil. Disponível em: http://www.correiosbrasil.org/historia-dos-correios/ . Acesso em: 18 set. 2021. 
FONTES-FILHO, Joaquim Rubens. A governança corporativa em empresas estatais brasileiras frente a Lei de Responsabilidade das Estatais (Lei $\mathrm{n}^{\circ}$ 13.303/2016). Revista Serviço Público, p. 181 - 209, Edição Especial: repensando o estado brasileiro. Brasília, 2019.

FORTINI, C.; SHERMAN, A. Governança corporativa e medidas preventivas contra a corrupção na administração pública: em enfoque à luz da Lei $\mathrm{n}^{\circ} 13.303 / 2016$. Revista de Administração Pública. Universidade Federal Fluminense, a2, v.2, n.1, jan/jun,2016.

GOMES CORREIA, T. O sistema postal brasileiro em transformação: propostas e mudanças na regulação do mercado e na reestruturação do modelo organizacional da Empresa Brasileira de Correios e Telégrafos (1994-2011). Rev. Adm. Pública, nov./dez, Rio de Janeir, 2014.

HITT, M.; A. IRELAND, R. D.; HOSKISSON, R. E. Administração estratégica: competitividade e globalização. São Paulo: Bookman, 2008.

MAZZALI, L. SOUZA, C. de A. F. S.; NEVES, R. O. Compartilhamento e aquisição de competências na estratégia da Empresa Brasileira de Correios e Telégrafos. Produção, v. 20, n. 2, abr./jun. 2010, p. 290-301. USCS, São Caetano do Sul.

PELLEGRINI, J. Empresas estatais federais: relações com o tesouro e valor. In Empresas estatais : políticas públicas, governança e desempenho. SILVA, Mauro Santos; SCHIMIDT, F.de H.; KLIASS, P. Brasília : Ipea, 2019.

ROMANO, Rogério Tadeu. A privatização da ECT. Disponível em:https://www.rogeriotadeuromano.jusbrasil.com.br/artigos/753. Acesso em: 28 set. 2021.

TEIXEIRA, O sistema postal brasileiro em transformação: propostas e mudanças na regulação do mercado e na reestruturação do modelo organizacional da Empresa Brasileira de Correios e Telégrafos (1994-2011). Rev. Adm. Pública 48 (6) • Dez 2014. Disponível em: http//:www.scielo.br/j/rap/a/7Cbz4SYhNm4fbB5VJZsPQsG/?lang=pt\#. Acesso em: 27 set. 2021. 